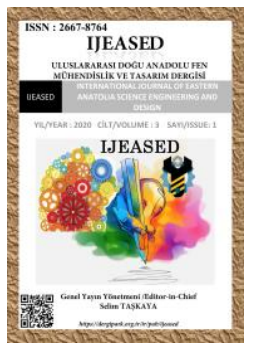

IJEASED INTERNATIONAL JOURNAL OF EASTERN ANATOLIA SCIENCE ENGINEERING AND DESIGN

Uluslararası Doğu Anadolu Fen Mühendislik ve Tasarım Dergisi ISSN: 2667-8764, 3(1), 333-349, 2021 https://dergipark.org.tr/tr/pub/ijeased

\title{
Polioksimetilen Kopolimerinin Su Jeti Tezgâhlarında İşlenebilirliğinin Taguchi Metodu Kullanılarak Optimizasyonu
}

\author{
Aliriza ALTINSOY ${ }^{1 *}$, Yusuf ARSLAN ${ }^{2}$ \\ ${ }^{1}$ Düzce Üniversitesi, Makine Mühendisliği, Düzce, 81000, Türkiye. \\ ${ }^{2}$ Düzce Üniversitesi Düzce Meslek Yüksekokulu, Makine ve Metal Teknolojileri Bölümü, Düzce, 81000, Türkiye.

\begin{tabular}{l|l|l|l}
\hline \multicolumn{1}{c|}{ Yazar Kimliği / Author ID (ORCID Number) } & \multicolumn{3}{|c}{ Makale Süreci / Article Process } \\
\hline "Sorumlu Yazar / Corresponding author: & Geliş Tarihi / Received Date $:$ & 18.12 .2020 \\
alirizaaltinsoy @duzce.edu.tr & Revizyon Tarihi / Revision Date : & 07.04 .2021 \\
\hline (iD) https://orcid.org/0000-0002-8429-9606 , A. Altınsoy & Kabul Tarihi / Accepted Date : & 19.04 .2021 \\
iD https://orcid.org/0000-0003-1731-5423, Y. Arslan & Yayım Tarihi / Published Date : & 15.07 .2021 \\
\hline
\end{tabular}

Alıntı / Cite: Altınsoy, A., Arslan, Y. (2021). Polioksimetilen Kopolimerinin Su Jeti Tezgâhlarında İşlenebilirliğinin Taguchi Metodu Kullanılarak Optimizasyonu, Uluslararası Doğu Anadolu Fen Mühendislik ve Tasarım Dergisi, 3(1), 333-349.

\section{Özet}

Mühendislik polimeri olan polioksimetilen kopolimer (POM-C) yüksek çekme mukavemeti, aşınma direnci ve boyut kararlılığı gibi mekanik özelliklerinden dolayı günümüzde havacılık, otomotiv ve gemi sanayinde faaliyet gösteren birçok sanayi alanında kullanılmaktadır. Bu polimerler kullanım alanlarına göre şekillendirilmesi gerekmektedir. Şekillendirme yöntemlerden bir tanesi de su jeti tezgahlarıdır. Kesme sonrası, talaş oluşum sorununu ortadan kaldırması nedeniyle su jeti ile kesme genelde çok sert ve kırılgan olmayan malzemeler için uygundur. Polimerler, bu malzeme grubuna girmemekle birlikte, kesme işlemi esnasında yüksek ısıların oluşmaması bundan dolayı polimerlerin yapısal olarak bozulmaması, daha küçük ve karmaşık şekillerin rahatlıkla işlenmesi, su jeti ile üretimin, diğer üretim metodlarına göre daha hızlı olması, aynı zamanda mühendislik polimerlerinin pahalı olması, uygulanan metotta daha az malzemenin israf olması polimerlerin su jeti tezgahlarında işlenmesinin başlıca sebeplerindendir. $\mathrm{Bu}$ çalışmada polioksimetilen kopolimerine 210, 260, $310 \mathrm{MPa}$ basınçta üç farklı ilerleme hızı ( 170, 240, $380 \mathrm{~mm} / \mathrm{dk}$ ), üç farklı aşındırıcı garnet miktarı $(150,250,350 \mathrm{~g} / \mathrm{dk})$ su jeti tezgâhında kesme işlemi gerçekleştirilmiştir. Deney sonuçlarındaki veriler sinyal - gürültü oranı $(\mathrm{S} / \mathrm{N})$, ANOVA analizi, ve regresyon yöntemi uygulanarak incelenmiştir. Yapılan çalışma sonuçlarında su jeti tezgâhında $260 \mathrm{MPa}$ basınçta $350 \mathrm{~g} / \mathrm{dk}$ garnet miktarı $170 \mathrm{~mm} / \mathrm{dk}$ ilerleme hızında yüzey pürüzlülüğünün diğer parametrelere göre daha düşük çıktığı, ilerleme hızının su jeti tezgahlarında en etkin parametre olduğu bulunmuştur.

Anahtar Kelimeler: Su jeti, Polioksimetilen, Yüzey pürüzlülüğü, Eğim Açısı. 


\title{
Optimization of Polyoxymethylene Copolymer Workability on Water-Jet Machines Using Taguchi Method
}

\begin{abstract}
Polyoxymethylene copolymer (pom-c), which is an engineering polymer, is used in many industries operating in aviation, automotive and ship industries today due to its mechanical properties such as high tensile strength, fly resistance and thermal resistance. These polymers need to be shaped according to their usage areas. Waterjet cutting is generally suitable for very hard and non-brittle materials, as it eliminates the problem of chip formation after cutting. Although polymers do not belong to this group of materials, high temperatures do not occur during the cutting process, therefore the polymers do not deteriorate structurally, smaller and complex shapes can be easily processed, production with water jet is faster than other production methods, at the same time, engineering polymers are expensive, Less material wasted in the method is one of the main reasons polymers are processed on waterjet looms. In this study, three different feed rates $(170,240,380 \mathrm{~mm} / \mathrm{min})$ and three different sand quantities $(150,250,350 \mathrm{~g} / \mathrm{min})$ were cut on a water jet machine at 210, 260, $310 \mathrm{MPa}$ pressure to the polyoxymethylene copolymer. The data in the experimental results were analyzed by applying the signal-to-noise ratio $(S / N)$, ANOVA analysis, and regression method. According to the results of the study, it was found that the sand amount of $350 \mathrm{~g} / \mathrm{min}$ at $260 \mathrm{MPa}$ pressure and $170 \mathrm{~mm} / \mathrm{min}$ feed rate was lower than the other parameters and the feed speed was the most effective parameter in water jet looms.
\end{abstract}

Keywords: Water jet, Polyoxymethylene, Surface roughness, Tilt Angle.

\section{Giriş}

Türkiye'de ve dünyada polimer sektörü hızlı bir gelişme göstermiştir. Polimerlere olan talebin artmasıyla birlikte kimya mühendisleri, tıp sektörü, tekstil mühendisleri, makine mühendisleri gibi meslek branşları da polimerler üzerinde çalışmalar gerçekleştirmiştir. Polimerlere artan taleple beraber kullanım alanlarına göre şekillendirilme ihtiyacı artmıştır (Chanda ve ark., 2007)

Talaşlı imalat aracılığıyla şekillendirilen numunelerin yüzey kalitesinin arttırılmasında ilerleme hızı, iş parçası veya kesici dönüş hızı gibi birçok parametre kullanılmaktadır. Yüzey kalitesi, birbirine temas ederek çalışan dişli, mil, yatak gibi sistemlerde numunelerin kolay aşınmaması için önemli bir faktördür. Malzemelerin işlenebilir olması için belirlenen parametrelerin değişmesi, yüzey kalitesini de etkiler (Akkurt 2009).

$\mathrm{Su}$ jeti tezgahlarında, basınçlı su, aşındırıcı ile beraber iş parçasının hedeflenen yüzeyine çarparak talaş kaldırma işlemi gerçekleşir. Su jeti kesim teknolojisi, termal bozulma olmaması, yüksek esneklik, yüksek işleme çok yönlülüğü, fiziksel temas olmadan kolay entegrasyon, düşük işleme kuvveti ve minimum çapak gibi bir dizi farklı avantaja sahiptir. Sonuç olarak, düz su jeti veya aşındırıcı su jeti işleme teknolojisi önemli bir üretim konusu haline gelmiştir ( Liu ve ark., 2019). İşlenmesi zor olan malzemelerin şekillendirilmesini kolaylaştıran su jeti tezgâhları, özellikle otomotiv, havacılık ve savunma sanayi gibi birçok endüstride yaygın olarak kullanılmaktadır. Proses maliyeti su ve aşındırıcı olduğundan düşüktür (Kulekçi, 2002) 
Su jeti tezgâhları ile kesme işleminde, 1sı oluşmadığından kesilen polimer numunelerde deformasyon görülmemekte, ayrıca insan sağlığı ve çevreye doğrudan zarar vermemektedir (Dong ve ark., 2014). Ancak, kesme işleminin çok yüksek basınçlarda yapılması nedeniyle insan sağlığını etkileyecek riskli bir durumun oluşmaması için emniyet tedbirlerine çok daha fazla önem verilmelidir.

Su jeti tezgâhlarında en önemli parametre yüzey kalitesi ve eğim açısıdır. Yapılan çalışmada araştırmacılar bu etkenleri azaltmak için çalışmışlardır (Liu ve ark., 2012; Mardı ve ark., 2017; Ishfaq ve ark., 2019) Şekil 1'de görüldüğü gibi kesme işlemi esnasında iş parçasına suyun en son temas ettiği çıkış bölgesi (sç), ilk temas ettiği giriş bölgesinden daha geniştir (sg) (Shanmugam ve ark., 2009).

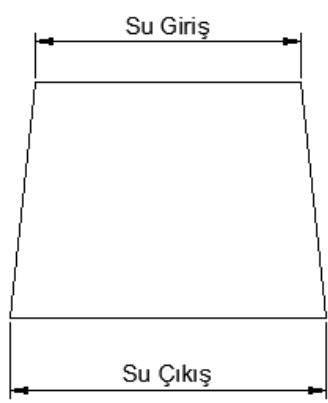

Şekil 1. Kesme sonrası oluşan eğim (Shanmugam ve ark., 2009).

Birçok araştırmacı paslanmaz çelik, kompozit malzemeler, granit, alüminyum gibi malzemelerde su jeti ile kesimini yaparak yüzey pürüzlülüğü ve eğim açısını değerlendirmiştir. (Schwartzentruber ve ark., 2017; Shanmugam ve ark., 2020; Akkurt ve ark., 2004; Karakurt ve ark., 2010).

Genellikle düşük mukavemete sahip olan ve ssıyla sertleșen polimerler, her zaman amorfturlar. Dolayısıyla, yüksek gerilme direnci oluşturdukları için kırılgandırlar. Termoplastik polimerler ise amorf veya kristal halde olabildikleri için nispeten daha sünek bir davranış sergilerler. Bu nedenle, su jeti tezgâhlarında, polimerlerin işlenebilir özelliklerinin çok kısıtlı olduğu, yapılan çalışmalarda gösterilmiştir

$\mathrm{Bu}$ çalışmada polioksimetilen kopolimer (pom-c) malzemesini farklı basınç, farklı garnet miktarı ve ilerleme hızında kesimi yapılarak giriş yüzey ve çıkış yüzey pürüzlülüğü, parça üzerindeki su giriş ve su çıkış ölçüleri değerlendirilerek eğim açılarında optimum parametreler belirlenmiştir. 


\section{Materyal ve Metot}

Polioksimetilen kopolimeri yüksek aşınma ve darbe direnci, mükemmel boyut kararlılığ1, yüksek termal dayanımı gibi özelliklerinden dolayı dişli, mafsal, kam gibi dinamik kuvvetlere maruz kalan malzemelerin üretiminde kullanılmaktadır (Jose ve Alagar, 2011). Polioksimetilenin teknik özellikleri Tablo 1'de verilmiştir.

Tablo 1. Polioksimetilen kopolimerin teknik özellikleri (Taşdemir, 2012)

\begin{tabular}{ll}
\hline Yoğunluk & $1,43 \mathrm{~g} / \mathrm{cm}^{3}$ \\
\hline Çekme Dayanımı & $79 \mathrm{MPa}$ \\
\hline Darbe Dayanımı & $15 \mathrm{kj} / \mathrm{m}^{2}$ \\
\hline Kopma Uzaması & $\% 37$ \\
\hline Ĕ̆ilme Mukavemeti & $106 \mathrm{MPa}$ \\
\hline Erime Sıcaklı̆̆ı & $182^{\circ} \mathrm{C}$ \\
\hline Cam Geçiş Sıcaklı̆̆ı & $-60^{\circ} \mathrm{C}$ \\
\hline Bilya Baskı Basıncı & $165 \mathrm{MPa}$ \\
\hline
\end{tabular}

Deneylerin yapıldığg N-WJL marka su jeti tezgâhına ait teknik özellikler, Tablo 2' de verilmiştir. Şekil 2' de gösterildiği gibi 15,6 mm kalınlığında olan numuneler, $60 \mathrm{~mm}$ uzunluğunda, $12,7 \mathrm{~mm}$ genişliğinde $90^{\circ}$ lik açıyla 80 mesh garnet aşındırıcı ile 27 adet numune işlenmiştir.

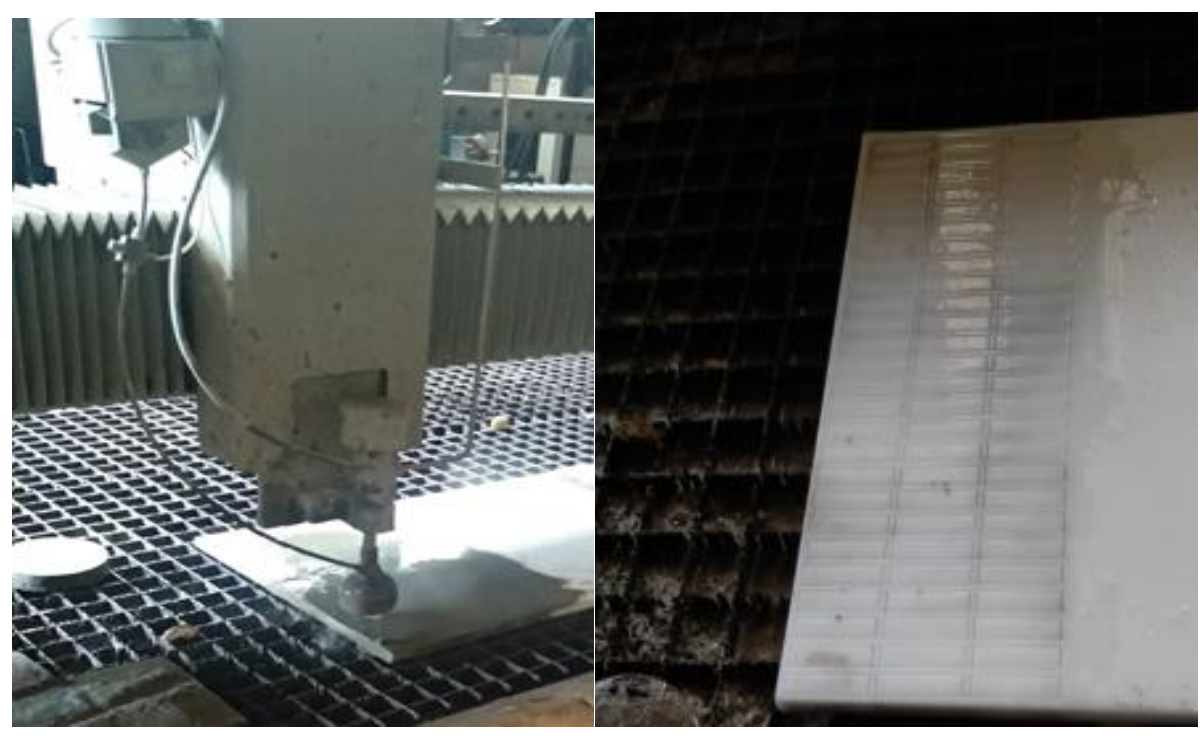

Şekil 2. Su jetinde işlenen numuneler 
Tablo 2. Su jeti tezgahı teknik özellikleri

\begin{tabular}{lcll}
\hline Pompa basıncı & $\leq 4000 \mathrm{bar}$ & $\begin{array}{l}\text { Nozulun parçaya } \\
\text { uzaklığı }\end{array}$ & $4 \mathrm{~mm}$ \\
\hline $\begin{array}{l}\text { Kesme sürecindeki } \\
\text { sıcaklık aralığı }\end{array}$ & $45-50{ }^{\circ} \mathrm{C}$ & Nozul duruş açısı & $90^{\circ}$ \\
\hline Aşındırıcı tipi & 80 mesh garnet & Nozul boyu & $76,2 \mathrm{~mm}$ \\
\hline Nozul çıkıs çapı & $0,76 \mathrm{~mm}$ & Tezgah kapasitesi & $2 \mathrm{~m} \mathrm{x} 4 \mathrm{~m}$ \\
\hline
\end{tabular}

\subsection{Yüzey Pürüzlülüğü Ölçümleri}

Yüzey pürüzlülük değerleri PCE-RT 1200 yüzey pürüzlülük cihazı ile ölçülmüştür. Numuneler işlenen yüzeyde 3 farklı noktasından ölçüm alınarak, yüzey pürüzlülüklerinin ortalamaları değerlendirilmiştir. Daha sonra taguchi metodu aracılığıyla en uygun verilere ulaşılmıştır. Sonuçlar optimum yüzey kalitesi S/N oranı ANOVA ve regresyon analizi sonucunda matematiksel model oluşturulmuştur. Yüzey pürüzlülük ölçümleri yapılan numunelerde, hassasiyeti 1/1000 mm olan dijital mikrometre yardımıyla istenilen ölçüye göre referans alınarak, eğim açılarının bulunması için numunelerin su giriş ve su çıkış bölgeleri ölçülerek, parametreler arasında karşılaştırma yapılmıştır. Sabit basınç ve sabit garnet miktarı farklı ilerleme hızlarında su jeti ile işlenmiş yüzeylerin SEM yardımıyla 70x büyüklükte görüntüleri alınarak aşınma türleri karşılaştırılmıştır.

\section{Taguchi Metodu}

Teknolojinin gelişmesi ile birlikte, endüstriyel alanda farklı yenilikler getirdi. Yenilikler kullanılırken en uygun değişkenler tayin etmek gerekir. Talaşlı imalatta zaman ve maddi kayıpları önlemek için yeni optimizasyon yöntemleri gerçekleştirilmiştir. Bu yöntemlerden bir tanesi taguchi yöntemidir. Bu yöntem aracılığıyla parametreler azaltılarak işlem değişkenlerini optimize etmek için kullanılır. Böylece yapılan analiz sonucunda deney değişkenleri büyük ölçüde azalır. Taguchi metodunda sonuçları değerlendirmek için bazı yöntemler kullanılır. Bu yöntemlerden bir tanesi sinyal gürültü oranı $(\mathrm{S} / \mathrm{N})$ aracılığıyla deney çıktılarını gösteren istenmeyen herhangi bir gürültü değeri için istenilen sinyal oranına dönüştürülür. Sinyal gürültü oranı $(\mathrm{S} / \mathrm{N})$ analizinde en küçük en iyi kalite özelliği kullanılır (Savaşkan ve ark., 2004; Gur ve ark., 2019).

En küçük en iyi : $\eta=\frac{s}{N s}=-10 \log \left(\frac{1}{n} \sum_{i=1}^{n} y_{i}^{2}\right)$ 
Burada n deneysel numunelerin sayısını, yi ise ölçülen deneysel verilerin ortalamasıdır (Gur ve ark., 2014).

Taguchi metodunda uygulanan ortogonal dizi tasarımını irdelemek için en uygun değişken ve etkileşim sayısının, çalışmanın amacı aynı zamanda deney bütçesi ve zamanının belirlenmesi büyük önem taşır (Roy 2010). Bu metotta kullanılan ksme parametreleri, Tablo 3 ’te verilmiştir.

Tablo 3. Su jeti tezgâhı kesme parametreleri

\begin{tabular}{lccc|ccc|ccc}
\hline Parametreler & \multicolumn{3}{c|}{ 1 } & \multicolumn{3}{c|}{ 2 } & \multicolumn{3}{c}{ 3 } \\
\hline Basınç ( MPa) & \multicolumn{3}{c}{210} & & 260 & & 310 \\
\hline Garnet Miktarı (g/dk) & 150 & 250 & 350 & 150 & 250 & 350 & 150 & 250 & 350 \\
\hline İlerleme Hızı ( mm/dk) & 170 & 240 & 380 & 170 & 240 & 380 & 170 & 240 & 380 \\
\hline
\end{tabular}

Taguchi metodunu uygulamadan önce birinci adım, denetleme etkenleri olarak seçilen, kesme parametrelerine uygun ortogonal dizinin belirlenmesidir. Bu çalışmada en uygun parametreyi belirlemek için $\mathrm{L}_{27}\left(3^{3}\right)$ dizisi belirlenmiştir.

\section{Bulgular ve Tartışma}

$\mathrm{Su}$ jeti ile kesme işlemi esnasında su giriş ve çıkış çalışma parametresi faktörlerinin her kombinasyonu için deneysel tasarım yoluyla Taguchi metodu uygulanarak değerlendirilmiştir. Parametrelerin optimizasyonu sinyal-gürültü $(\mathrm{S} / \mathrm{N})$ oranları ile sağlanmıştır. Yapılan çalışmada elde edilen sonuçlarda istenen yüzey kalitesinin minimum değerler istendiğinden sinyal - gürültü $(\mathrm{S} / \mathrm{N})$ oranın “en küçük en iyi” koşuluna göre sonuçlar oluşturulmuştur. Tablo 4'de yüzey pürüzlülüğü ve $\mathrm{S} / \mathrm{N}$ oranlarını göstermektedir. 
Tablo 4. Deney sonuçların neticesinde bulunan yüzey pürüzlülüğü değerleri ve S/N oranları

\begin{tabular}{|c|c|c|c|c|c|c|c|}
\hline \multirow[b]{2}{*}{$\begin{array}{l}\text { Sira } \\
\text { no }\end{array}$} & \multirow{2}{*}{$\begin{array}{l}\text { 1.Parametre } \\
\text { Basıç (MPa) }\end{array}$} & \multirow{2}{*}{$\begin{array}{l}\text { 2.Parametre } \\
\text { Garnet } \\
\text { Miktarı } \\
\text { (g/dk) }\end{array}$} & \multirow{2}{*}{$\begin{array}{l}\text { 3.Parametre } \\
\text { İlerleme Hızı } \\
(\mathrm{mm} / \mathrm{dk})\end{array}$} & \multicolumn{2}{|c|}{$\begin{array}{l}\text { Yüzey Pürüzlülük } \\
\text { Değerleri }(\mu \mathrm{m})\end{array}$} & \multicolumn{2}{|c|}{$\begin{array}{l}\text { Sinyal ve Gürülttü } \\
\text { Oranları ( S/N) }\end{array}$} \\
\hline & & & & $\begin{array}{l}\mathrm{Ra}(\mathrm{Su} \\
\text { Giriş) } \\
\text { Ortalama }\end{array}$ & $\begin{array}{l}\mathrm{Ra}(\mathrm{Su} \\
\text { Çıkış) } \\
\text { Ortalama }\end{array}$ & $\begin{array}{l}\mathrm{S} / \mathrm{N} \\
\text { Oranı(Su } \\
\text { Giriş) }\end{array}$ & $\begin{array}{l}\text { S/N } \\
\text { Oranı(Su } \\
\text { Çıkış) }\end{array}$ \\
\hline 1 & \multirow{9}{*}{210} & 150 & 170 & 6.681 & 6.920 & -16.4968 & -16.8021 \\
\hline 2 & & 150 & 240 & 6.524 & 9.680 & -16.2903 & -19.7175 \\
\hline 3 & & 150 & 380 & 8.054 & 10.252 & -18.1202 & -20.2162 \\
\hline 4 & & 250 & 170 & 6.081 & 6.670 & -15.6795 & -16.4825 \\
\hline 5 & & 250 & 240 & 6.201 & 6.634 & -15.8492 & -16.4355 \\
\hline 6 & & 250 & 380 & 7.267 & 9.680 & -17.2271 & -21.3489 \\
\hline 7 & & 350 & 170 & 5.467 & 5.917 & -14.7550 & -15.4420 \\
\hline 8 & & 350 & 240 & 5.467 & 6.561 & -14.7550 & -16.3394 \\
\hline 9 & & 350 & 380 & 6.321 & 8.907 & -16.0157 & -18.9946 \\
\hline 10 & \multirow{9}{*}{260} & 150 & 170 & 6.441 & 7.827 & -16.1791 & -17.8719 \\
\hline 11 & & 150 & 240 & 7.001 & 8.507 & -16.9032 & -18.5955 \\
\hline 12 & & 150 & 380 & 6.587 & 8.819 & -16.3738 & -23.9786 \\
\hline 13 & & 250 & 170 & 5.028 & 5.896 & -14.0279 & -15.4111 \\
\hline 14 & & 250 & 240 & 6.107 & 6.887 & -15.7166 & -16.7606 \\
\hline 15 & & 250 & 380 & 6.614 & 8.720 & -16.4093 & -18.8103 \\
\hline 16 & & 350 & 170 & 5.013 & 5.840 & -14.0020 & -15.3283 \\
\hline 17 & & 350 & 240 & 5.600 & 6.547 & -14.9638 & -16.3208 \\
\hline 18 & & 350 & 380 & 6.014 & 7.481 & -15.5833 & -17.4792 \\
\hline 19 & \multirow{9}{*}{310} & 150 & 170 & 6.441 & 7.347 & -16.1791 & -17.3222 \\
\hline 20 & & 150 & 240 & 6.547 & 7.281 & -16.3208 & -17.2438 \\
\hline 21 & & 150 & 380 & 6.680 & 9.480 & -16.4955 & -20.4072 \\
\hline 22 & & 250 & 170 & 5.960 & 6.934 & -15.5049 & -16.8197 \\
\hline 23 & & 250 & 240 & 5.920 & 7.294 & -15.4464 & -17.2593 \\
\hline 24 & & 250 & 380 & 6.880 & 7.801 & -16.7518 & -17.8430 \\
\hline 25 & & 350 & 170 & 5.907 & 6.554 & -15.4273 & -16.3301 \\
\hline 26 & & 350 & 240 & 6.294 & 6.667 & -15.9785 & -16.4786 \\
\hline 27 & & 350 & 380 & 7.054 & 7.627 & -16.9687 & -17.6471 \\
\hline
\end{tabular}




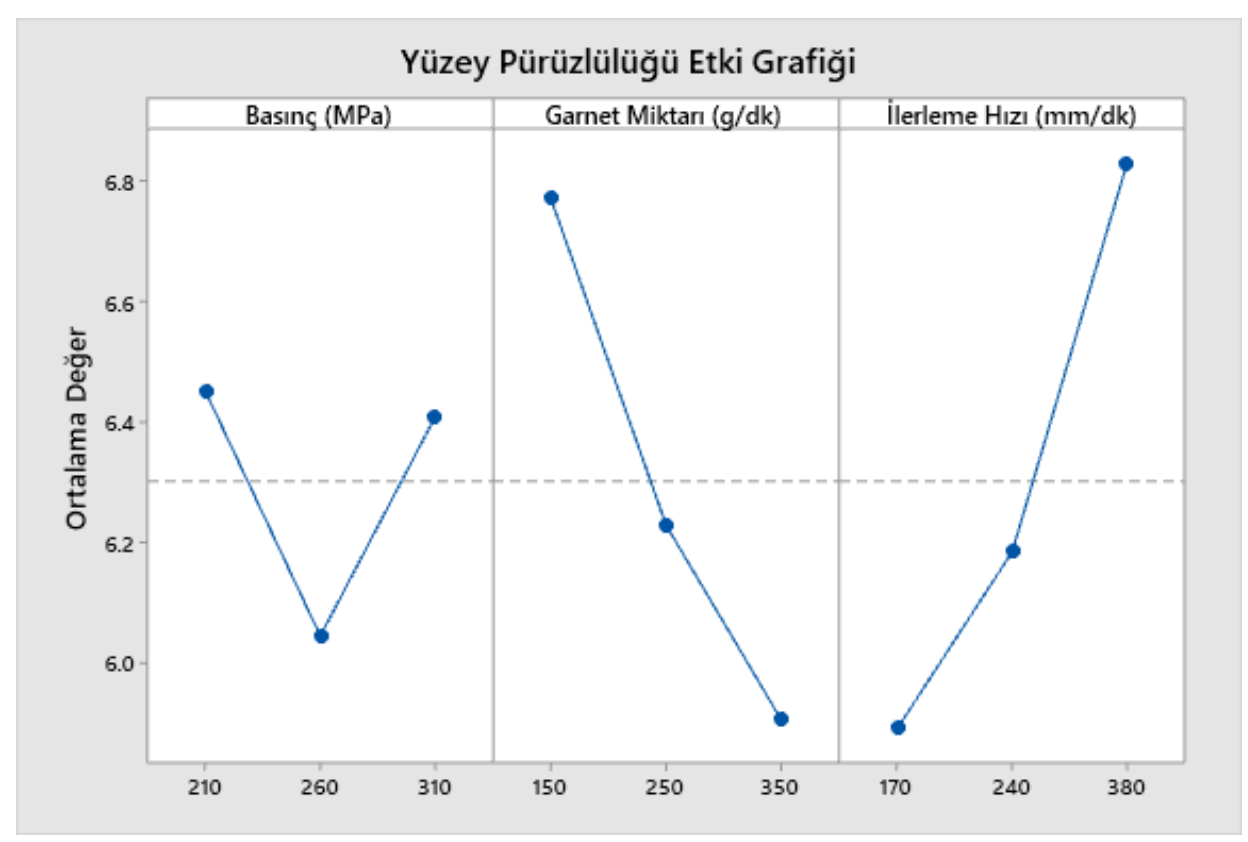

Şekil 3. Taguchi metodu sonrası yüzey pürüzlülüğü etki grafiği

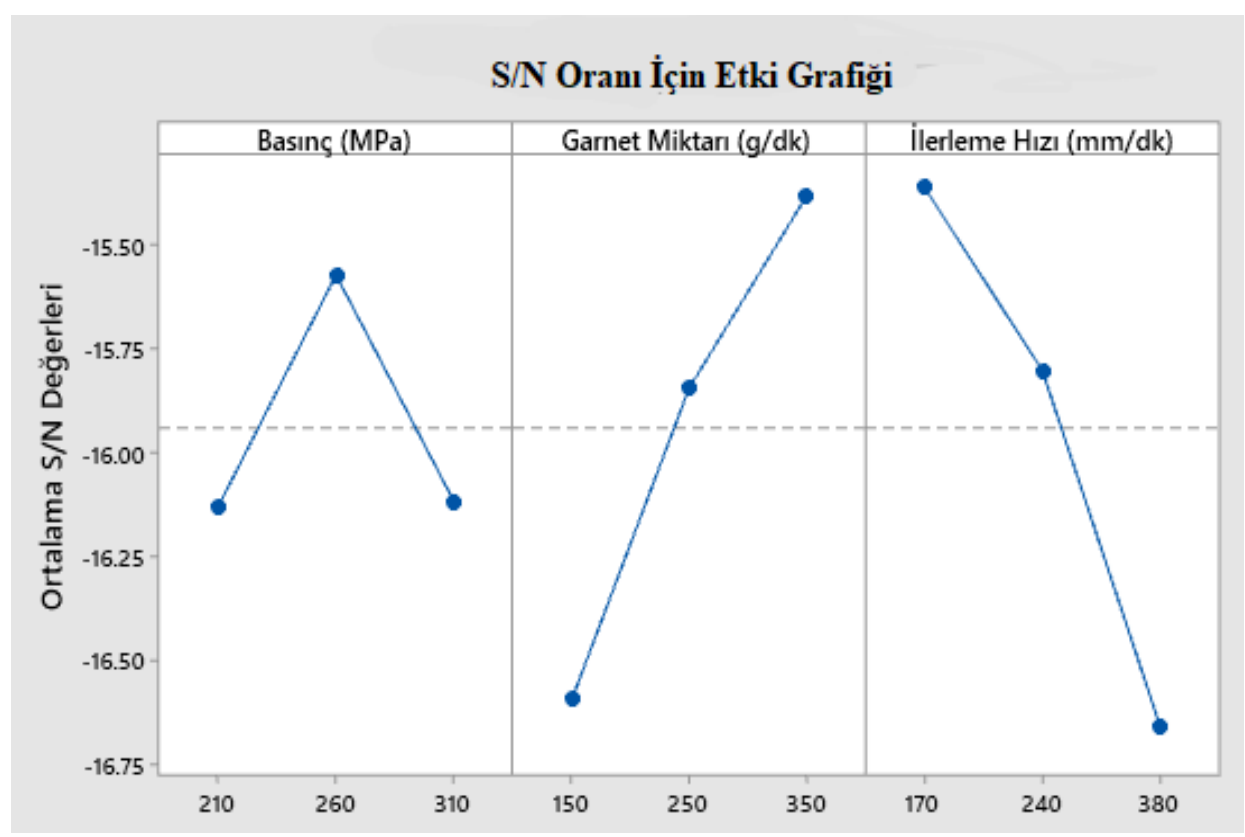

Şekil 4. Taguchi metodu sonrası $\mathrm{S} / \mathrm{N}$ oranı etki grafiği

Şekil 3 ve Şekil 4 'de işlenen yüzey üzerinde, Taguchi L 27 deney tasarımı ile elde edilen yüzey pürüzlülüğü etki grafiği ve $\mathrm{S} / \mathrm{N}$ oranı etki grafiği sırasıyla verilmiştir. Polioksimetilen kopolimeri kontrol faktörleri arasında en etkili olan parametre, her iki şekil içinde belirlenmiştir. Şekiller incelendiğinde $260 \mathrm{MPa}$ basınç, $350 \mathrm{gr} / \mathrm{dk}$ garnet miktarı ve $170 \mathrm{~mm} / \mathrm{dk}$ ilerleme hızında, en düşük yüzey pürüzlülüğü elde edilmiştir. 
Tablo 4'teki verilerin etki grafikleri, Şekil 5 ve Şekil 6'da göstermektedir. Yüzey pürüzlülüğü değerini en minimum değere azaltmak için kontrol faktörlerinin optimum işleme parametreleri oluşan bu grafikler aracılığgyla kolaylıkla belirlenir.

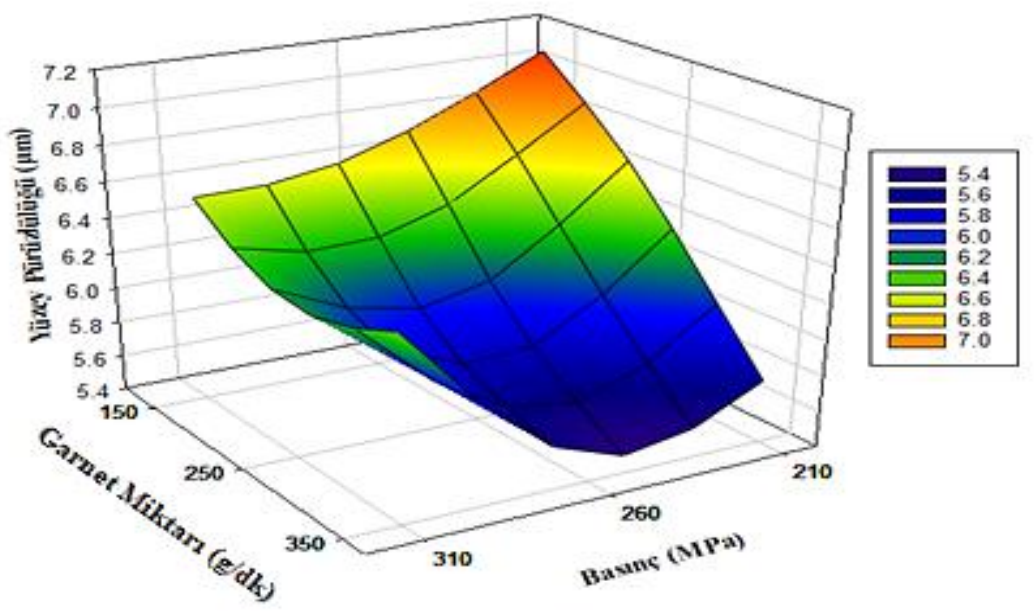

Şekil 5. Basınç ve aşındırıcı garnet miktarının yüzey pürüzlülügüne etkisi

Deney parametrelerine ayrılmış, çalışma sonuçlarına göre yüzey pürüzlülüğü Şekil 5 ve Şekil 6' da verilmiştir. Şekil 5' de basınç ve garnet miktarının yüzey pürüzlülüğüne etkisi incelenmiştir. Uygulanan parametrelerde minimum basınç ve minimum garnet miktarında yüzey pürüzlülüğünde maksimum artış olduğu görülmektedir. Aynı zamanda maksimum garnet miktarı ve maksimum basınç miktarında da yüzey pürüzlülüğün arttığı anlaşılmştır. En düşük yüzey pürüzlülüğü $260 \mathrm{MPa}$ basınç, $350 \mathrm{~g} / \mathrm{dk}$ garnet miktarında olduğu tespit edilmiştir.

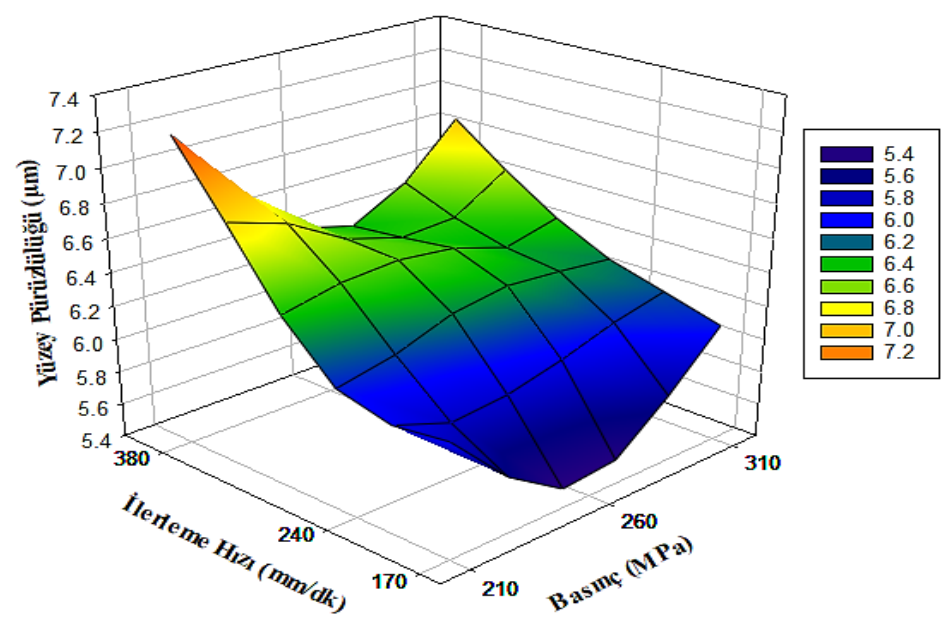

Şekil 6. Basınç ve ilerleme hızının yüzey pürüzlülüğ̈̈ne etkisi 
Şekil 6 incelendiğinde $210 \mathrm{MPa}$ ve $310 \mathrm{MPa}$ basınçta her iki parametre için ilerlemenin artırılması yüzey pürüzlülüğünde maksimum artışa neden olmuştur. İlerlemenin yüzey pürüzlülüğünde en önemli bir etken olduğu anlaşılmıştır. İlerleme hızı arttıkça yüzey pürüzlülüğünün arttığı, ilerleme hızı azaldıkça yüzey pürüzlülüğünün azaldığı görülmektedir. En düşük yüzey pürüzlülüğü $260 \mathrm{MPa}$ basınç ve $170 \mathrm{~mm} / \mathrm{dk}$ ilerleme hızında olduğu saptanmıştır.

\subsection{Anova Yardımıyla Veri Analizi}

ANOVA, deney tasarımında kullanılan parametrelerin etkileşimini öğrenmek için kullanılan yöntemdir (Tabachnick ve Fidell 2007 ; Akıncıoğlu ve ark., 2020). Sabit basınçta, garnet miktarı ve ilerleme hızının yüzey kalitesine etkisi ANOVA yardımıyla \% 95 güven düzeyinde incelenmiştir. Deneysel verilere göre yüzey pürüzlülüğü ve $\mathrm{S} / \mathrm{N}$ oranları sırasıyla Tablo 5 ve Tablo 6' da verilmiştir.

Tablo 5. Yüzey pürüzlülüğü için ANOVA analizi

\begin{tabular}{lllllll}
\hline Parametre & $\begin{array}{l}\text { Serbestlik } \\
\text { Derecesi } \\
\text { (Df) }\end{array}$ & $\begin{array}{l}\text { Kareler } \\
\text { Toplamı } \\
\text { (SS) }\end{array}$ & $\begin{array}{l}\text { Kareler } \\
\text { Ortalaması } \\
\text { (MS) }\end{array}$ & $\begin{array}{l}\text { F } \\
\text { Değeri }\end{array}$ & $\begin{array}{l}\text { P } \\
\text { Değeri }\end{array}$ & $\begin{array}{l}\text { Parametre Etkisi } \\
(\%)\end{array}$ \\
\hline Basınç & 2 & 0.8989 & 0.4495 & 2.77 & 0.08704 & $\% 7.64$ \\
\hline $\begin{array}{l}\text { Garnet } \\
\text { Miktarı }\end{array}$ & 2 & 3.4689 & 1.7344 & 10.67 & 0.00070 & $\% 29.46$ \\
\hline $\begin{array}{l}\text { İlerleme } \\
\text { Hızı }\end{array}$ & 2 & 4.1545 & 2.0773 & 12.78 & 0.00027 & $\% 35.29$ \\
\hline Hata & 20 & 3.2508 & 0.1625 & & & $\% 27.61$ \\
\hline Toplam & 26 & & & & & $\% 100.00$ \\
\hline
\end{tabular}

Tablo 6. $\mathrm{S} / \mathrm{N}$ oranları için anova analizi

\begin{tabular}{lllllll}
\hline Parametre & $\begin{array}{l}\text { Serbestlik } \\
\text { Derecesi } \\
\text { (Df) }\end{array}$ & $\begin{array}{l}\text { Kareler } \\
\text { Toplamı } \\
\text { (SS) }\end{array}$ & $\begin{array}{l}\text { Kareler } \\
\text { Ortalamas } \\
\text { (MS) }\end{array}$ & $\begin{array}{l}\text { F } \\
\text { Değeri }\end{array}$ & $\begin{array}{l}\text { P } \\
\text { Değeri }\end{array}$ & $\begin{array}{l}\text { Parametre Etkisi } \\
(\%)\end{array}$ \\
\hline Basınc & 2 & 0.00802 & 0.00802 & 0.04 & 0.083614 & $\% 0.07$ \\
\hline $\begin{array}{l}\text { Garnet } \\
\text { Miktarı }\end{array}$ & 2 & 3.39649 & 3.39649 & 18.53 & 0.000264 & $\% 28.85$ \\
\hline $\begin{array}{l}\text { Ilerleme } \\
\text { Hızı }\end{array}$ & 2 & 4.15234 & 4.15234 & 22.65 & 0.000085 & $\% 35.27$ \\
\hline Hata & 20 & 4.21631 & 0.18332 & & & $\% 35.81$ \\
\hline Toplam & 26 & & & & & $\% 100.00$ \\
\hline
\end{tabular}

Tablo 5'te yüzey pürüzlülügü için ANOVA analizinde basınç etkisi $\% 0.07$ garnet miktarı \% 29.46 ilerleme hızının \% 35.29, hata oranının \% 27,61 olduğu görülmektedir. Su jeti tezgâhları için, ilerleme hızının etkin faktör olduğu anlaşılmıştır. Tablo 6' da S/N oranları için yapılan ANOVA analizinde basınç etkisi \% 0.07, garnet miktarı \% 28.85, ilerleme hızı \% 35.57 olarak bulunmuştur. 
Her iki tablo karşılaştırıldığında en önemli parametre ilerleme hızı olurken, basınç etkisinin en etkisiz parametre olduğu anlaşılmıştır. Polimer esaslı kompozit malzemelerin su jeti ile işlenmesinde düşük ilerleme hızı ile malzemeye daha az zarar verilerek düşük yüzey pürüzlülügü elde edilmiştir. Yapılan çalışma sonuçları literatürü desteklemektedir (Mayuet ve ark., 2015). Ayrıca Alberdi ve ark., (2015) yapmış olduğu çalışmada düşük basıncın ve yüksek ilerleme hızının malzemeye daha fazla zarar verdiği ve yüzey pürüzlülüğünün artmasına neden olduğunu tespit etmiştir. Su jeti tezgahlarında ilerleme hızının, yüzey pürüzlülüğünün azaltılmasında önemli bir parametre olduğu anlaşılmıştır.

Şekil 7 incelendiğinde normal olasılık grafiği, regresyon modeli denklemine kıyasla tek tek değerlerin sapmasını gösterir (Nas ve Özbek, 2020). Çizgi etrafındaki kümelenmiş noktalar düşük sapma gösterir. Yüzey için kalan (kalıntı) grafikleri pürüzlülüğü göstermektedir. Şekil 7'de normal olasılık grafiğinin, hata noktalarının normal olarak dağıldığını, neredeyse doğrusal bir tepki gösterdiği görülmüştür.

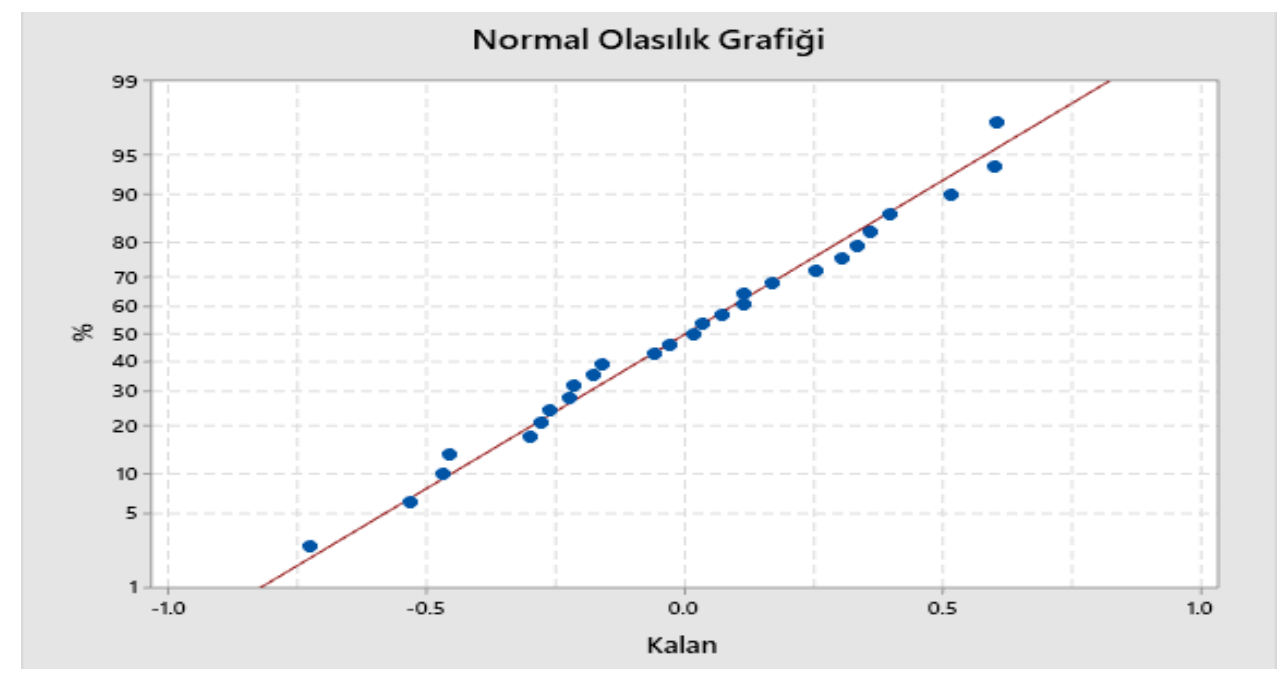

Şekil 7. Yüzey pürüzlülüğü ve serbest yüzey aşınmasının S / N oranları için artık grafikler

\subsection{Deneysel Sonuçlar İçin Regresyon Yöntemi}

Bağımlı değişkenin, bir veya daha fazla bağımsız değişken ile modellenerek formülasyon oluşturmak için Regresyon yöntemi kullanılmıştır (Nas ve Öztürk, 2018; Kıvak, 2014 ). Bu çalışmada, sabit basınçta, yüzey kalitesi ile garnet miktarı ve ilerleme hızı arasındaki ilişki regresyon yöntemiyle belirlenmiştir. $\mathrm{Bu}$ yöntemle, sonraki çalışmalar için en uygun yüzey kalitesinin belirlenmesi sağlanmıştır. Basınç artışıyla yüzey pürüzlülüğü arasında ters bir korelasyonun oluştuğu, regresyon yöntemiyle belirlenen ve aşağıda verilen formülden anlaşılmaktadır. 
Yüzey Pürüzlülüğü $(\mu \mathrm{m})=6,315-0,00042$ (Basınç) - 0,00434 (Garnet Miktarı) + 0,004492 (İlerleme Hiz1 )

\subsection{Parametrelere Göre En Uygun Eğim Açısının Bulunması}

Su jeti tezgâhında yapılan kesme işlemi sırasında, özellikle iş parçasının çıkış noktasında, aşındırıcıların etkisini kaybetmesi mümkündür. Literatürde, iş parçasının kalınlığı ile birlikte sürtünme kuvvetlerinin de arttığı dolayısıyla yüzey kalitesinin azaldığı, eğim açısının ise arttı̆̆ görülmüştür. Ayrıca, kalınlık artırılarak ilerleme hızı düşürüldüğünde basınç artışıyla birlikte yüzey kalitesini iyileştirmek mümkündür. (Vikram ve Babu, 2002).

Şekil 8'de görüldüğü gibi ilerleme hızı artırılarak işlenmiş numunede suyun giriş kısmındaki yüzeyin daha kaliteli olduğu ancak ilerleme hızının artmasından dolayı aşındırıcının etkisini kaybetmesinden çıkış yüzeyinin bozulduğu görülmektedir.

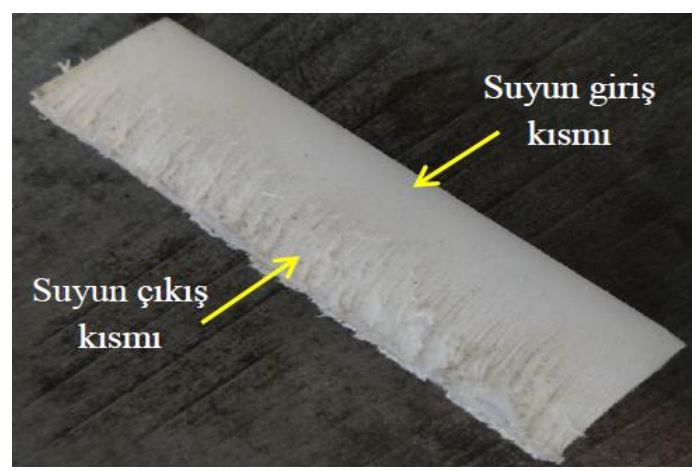

Şekil 8. Kesim esnasında oluşan yüzey 
Tablo 7. İşlenen numunelerin eğim açısının belirlenmesi

\begin{tabular}{|c|c|c|c|c|c|}
\hline Basınç (MPa) & $\begin{array}{l}\text { Garnet } \\
\text { Miktarı } \\
\text { (g/dk) }\end{array}$ & $\begin{array}{l}\text { İlerleme Hızı } \\
(\mathbf{m m} / \mathbf{d k})\end{array}$ & $\begin{array}{l}\text { Su Giriş } \\
\text { Ölçüsü }(\mu \mathrm{m})\end{array}$ & $\begin{array}{l}\text { Su Çıkış } \\
\text { Ölçüsü }(\mu \mathrm{m})\end{array}$ & $\begin{array}{l}\text { Eğim Açısı } \\
\left({ }^{\circ}\right)\end{array}$ \\
\hline \multirow{9}{*}{210} & 150 & 170 & 12,737 & 13,092 & 0,6519 \\
\hline & 150 & 240 & 12,863 & 13,159 & 0,5436 \\
\hline & 150 & 380 & 12,956 & 13,235 & 0,5123 \\
\hline & 250 & 170 & 12,690 & 12,990 & 0,5509 \\
\hline & 250 & 240 & 12,676 & 13,023 & 0,6372 \\
\hline & 250 & 380 & 12,742 & 13,094 & 0,6464 \\
\hline & 350 & 170 & 12,566 & 12,842 & 0,5068 \\
\hline & 350 & 240 & 12,590 & 12,879 & 0,5307 \\
\hline & 350 & 380 & 12,605 & 12,986 & 0,6996 \\
\hline \multirow{9}{*}{260} & 150 & 170 & 12,875 & 13,038 & 0,3287 \\
\hline & 150 & 240 & 12,894 & 13,054 & 0,2938 \\
\hline & 150 & 380 & 12,986 & 13,144 & 0,2901 \\
\hline & 250 & 170 & 12,851 & 12,974 & 0,2259 \\
\hline & 250 & 240 & 12,781 & 12,866 & 0,2295 \\
\hline & 250 & 380 & 12,932 & 13,119 & 0,3434 \\
\hline & 350 & 170 & 12,767 & 12,855 & 0,1671 \\
\hline & 350 & 240 & 12,836 & 12,967 & 0,2406 \\
\hline & 350 & 380 & 12,931 & 13,094 & 0,2993 \\
\hline \multirow{9}{*}{310} & 150 & 170 & 12,874 & 12,996 & 0,2241 \\
\hline & 150 & 240 & 12,928 & 13,061 & 0,2442 \\
\hline & 150 & 380 & 13,014 & 13,208 & 0,3563 \\
\hline & 250 & 170 & 12,842 & 12,980 & 0,2534 \\
\hline & 250 & 240 & 12,880 & 13,111 & 0,4242 \\
\hline & 250 & 380 & 12,949 & 13,189 & 0,4407 \\
\hline & 350 & 170 & 12,793 & 12,935 & 0,2608 \\
\hline & 350 & 240 & 12,824 & 13,010 & 0,3416 \\
\hline & 350 & 380 & 12,892 & 13,138 & 0,4517 \\
\hline
\end{tabular}

Tablo 7 incelendiğinde, $210 \mathrm{MPa}$ basınçta eğim açılarının diğer basınçlara göre arttı̆̆ı, ancak $260 \mathrm{MPa}$ basınç altında işlenen numunelerin, $310 \mathrm{MPa}$ ve $210 \mathrm{MPa}$ basınç altında işlenen numunelere göre eğim açılarının azaldığı gözlemlenmiştir. Uygulanan basınç parametrelerinde $260 \mathrm{MPa}$ basınç optimum parametre olarak bulunmuştur. İrana Wong ve ark., (2018) azalan eğim açısının ilerleme hızının azalmasından kaynaklandığını belirtmiştir. Tabloda eğim açılarında genel olarak ilerleme hızı azaldıkça eğim açısında azalma olduğu görülmüş̧tür. Ancak Tablo 7'de uygulanan basınçlar altında, düşük basınç ve düşük garnet miktarında, ilerleme hızı arttıkça eğim açılarında azalma olduğu görülmektedir. Suyun giriş kısmında kesme işlemi daha kolayken, suyun çıkış kısmında düşük basınç ve düşük garnet miktarından dolayı kesme özelliğinin azalmasından dolayı eğim açısının arttı̆̆ı, bundan dolayı eğim açılarında azalma isteniyorsa ilerleme hızının azaltılmasının yanı sıra uygulanan basıncın ve garnet miktarının arttırılması gerektiği kanısına varılmıştır. En küçük eğim açısı $260 \mathrm{MPa}$ 
Altınsoy, A., Arslan, Y., Uluslararası Doğu Anadolu Fen Mühendislik ve Tasarım Dergisi / International Journal of Eastern Anatolia Science Engineering and Design (IJEASED)

(2021) 3(1):333-349

basınç, $350 \mathrm{gr} / \mathrm{dk}$ garnet miktarı ve $170 \mathrm{~mm} / \mathrm{dk}$ ilerleme hızında belirlenirken, en büyük eğim açısı $210 \mathrm{MPa}$ basınç, $350 \mathrm{gr} / \mathrm{dk}$ garnet miktarı ve $380 \mathrm{~mm} / \mathrm{dk}$ ilerleme hızında bulunmuştur.
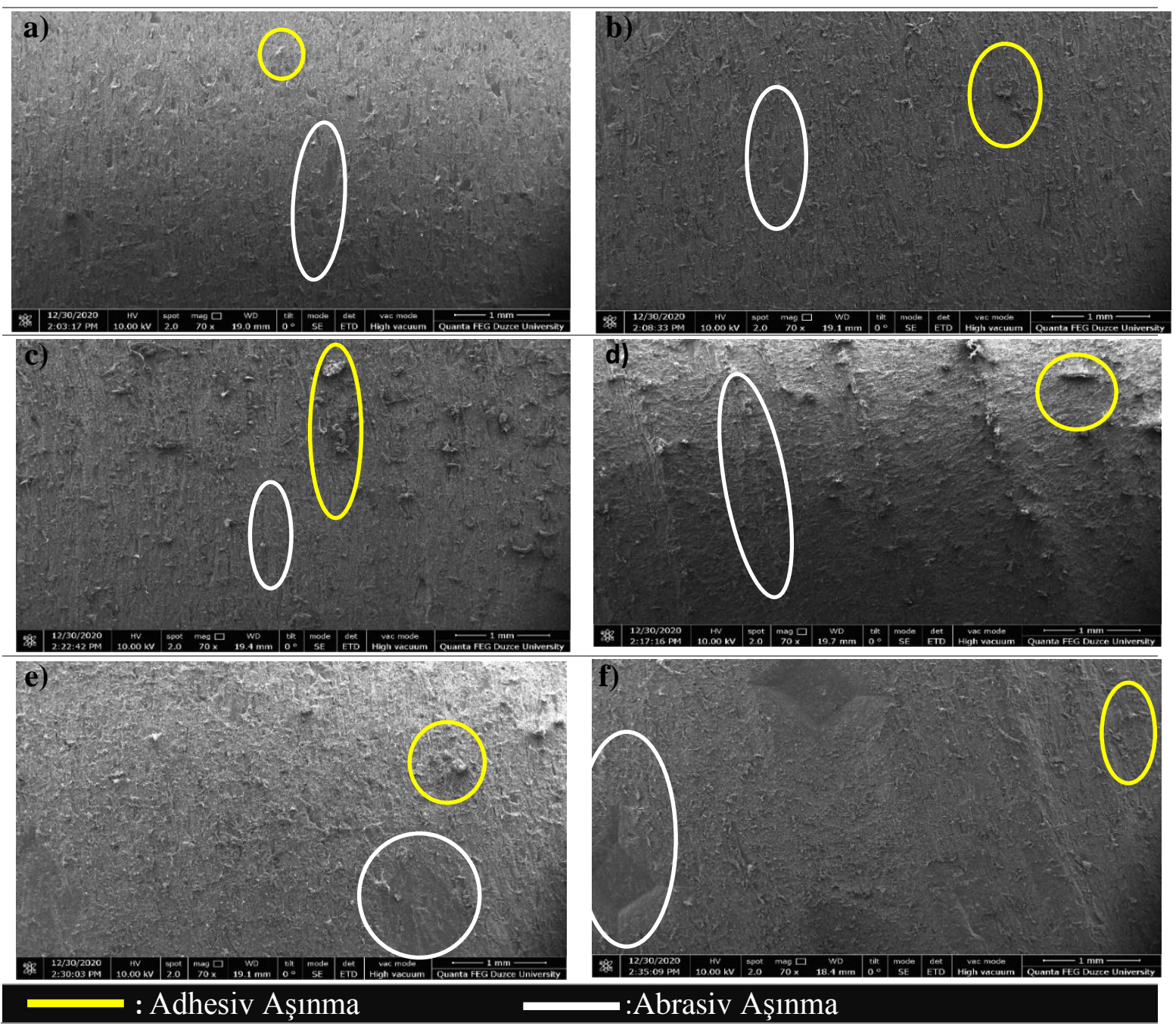

Şekil 9. Su jeti ile $260 \mathrm{MPa}$ basınç, $250 \mathrm{~g} / \mathrm{dk}$ garnet miktarı ve $170 \mathrm{~mm} / \mathrm{dk}$ ilerleme hızında, su ve garnetin numuneye giriş yüzeyinin SEM görüntüsü (a), suyun ve garnetin numuneden çıkış yüzeyinin SEM görüntüsü (b) . 260 basınç, $250 \mathrm{~g} / \mathrm{dk}$ garnet miktarı ve $240 \mathrm{~mm} / \mathrm{dk}$ ilerleme hızında su ve garnetin numuneye giriş yüzeyinin SEM görüntüsü (c), suyun ve garnetin numuneden çıkış yüzeyinin SEM görüntüsü (d). 260 basınç, $250 \mathrm{~g} / \mathrm{dk}$ garnet miktarı ve $380 \mathrm{~mm} / \mathrm{dk}$ ilerleme hızında, su ve garnetin numuneye giriş yüzeyinin SEM görüntüsü (e). suyun ve garnetin numuneden çıkış yüzeyinin SEM görüntüsü (f).

Şekil 9'da sabit basınç ve sabit garnet miktarının farklı ilerleme hızlarında aşınmaya etkisi incelenmiştir. Aşınma türlerinin yoğun olduğu bölgeler daireler aracılığıyla belirlenmiştir. 170 $\mathrm{mm} / \mathrm{dk}$ ilerleme hızında işlenen numunede su ve garnet giriş yüzeyinde abrasiv aşınmaların görüldüğ̈̈, adhesiv aşınmaların daha az olduğu görülmektedir (a). Su ve garnet çıkış yüzeyinde 
abrasiv aşınmaların yanı sıra adhesiv aşınmaların oluştuğu görülmektedir (b). $240 \mathrm{~mm} / \mathrm{dk}$ ilerleme hızında su ve garnet giriş yüzeyinde adhesiv aşınmaların çoğunlukta olduğu (c), su ve garnet çıkış yüzeyinde abrasiv aşınmaların çoğunlukta olduğu görülmüştür (d). $380 \mathrm{~mm} / \mathrm{dk}$ ilerleme hızında işlenen numunenin su ve garnet giriş yüzeyinde abrasiv aşınmaların geniş bir alana yayıldığı (e), su ve garnet çıkış yüzeyinde abresiv aşınmaların çok derin ve geniş alanda olduğu tespit edilmiştir (f).

\section{Sonuçlar ve Öneriler}

Yapılan çalışmalardaki parametrelerin yüzey pürüzlülüğünde en uygun kombinasyonu 260 MPa basınç, $350 \mathrm{~g} / \mathrm{dk}$ garnet miktarı ve $170 \mathrm{~mm} / \mathrm{dk}$ ilerleme hızında bulunmuştur. En küçük eğim açısı, $260 \mathrm{MPa}$ basınç, $350 \mathrm{gr} / \mathrm{dk}$ garnet miktarı, $170 \mathrm{~mm} / \mathrm{dk}$ ilerleme hızında elde edilmiştir. En büyük eğim açısında, basınç $210 \mathrm{MPa}$, garnet miktarı $350 \mathrm{gr} / \mathrm{dk}$ ve ilerleme hızı ise $380 \mathrm{~mm} / \mathrm{dk}$ olarak ölçülmüştür. Anova analizi sonuçlarında, ilerleme hızının \% 35.29 garnet miktarının \% 29.46, basınç etkisinin \% 7.64 olduğu görülmüştür. İlerleme \% 35.29 oranla hızının su jeti tezgâhlarında en önemli faktör olduğu, basıncın \%7.64 oranla ise en etkisiz faktör olduğu anlaşılmıştır. Üç boyutlu grafikler değerlendirildiğinde ilerleme hızının artması yüzey pürüzlülüğünü olumsuz yönde etkilediği, yüksek ilerleme hızında nozuldan gelen suyun ve garnetin aynı noktaya daha az etki ettiği bundan dolayı suyun çıkış kısmında genişleme olduğu anlaşılmıştır. İlerleme hızının azalması yüzey pürüzlülüğünün azalmasına sebep olduğu tespit edilmiştir.

Literatür incelendiğinde polimer malzemelerin su jeti ile işlenebilirliğinin çok az olduğu daha birçok mühendislik polimerinin su jeti tezgahı ile işlenebilirliğinin yüzey kalitesine etkisi gibi paremetrelerin uygulanmadığı görülmüştür. Yapılan çalışma diğer polimer türlerinin bu proseste işlenebilirliğine 1şık tutacaktır.

\section{Yazarların Katkısı}

Çalışmada her iki yazar da eşit oranda katkı sunmuştur.

\section{Çıkar Çatışması Beyanı}

Yazarlar arasında herhangi bir çıkar çatışması bulunmamaktadır.

\section{Araştırma ve Yayın Etiği Beyanı}

Yapılan çalışmada, araştırma ve yayın etiğine uyulmuştur. 
Altınsoy, A., Arslan, Y., Uluslararası Doğu Anadolu Fen Mühendislik ve Tasarım Dergisi / International Journal of Eastern Anatolia Science Engineering and Design (IJEASED)

(2021) 3(1):333-349

\section{Teșekkür}

Yazarlar, Düzce Üniversitesi Bilimsel Araştırma Projeleri (Proje no: 2019.21.01.1047)

Koordinatörlüğü tarafından, destekler için teşekkür ederler.

\section{Kaynaklar}

Akincioğlu, S., Gökkaya, H., Akincioğlu, G., \& Karataş, M. A. (2020). Taguchi optimization of surface roughness in the turning of Hastelloy C22 super alloy using cryogenically treated ceramic inserts. Proceedings of the Institution of Mechanical Engineers, Part C: Journal of Mechanical Engineering Science, 234(19), 3826-3836.

Akkurt, A. (2009). AISI 1030 Çeliğinin Aşındırıcılı Su Jeti İle Kesilmesinde Yüzey Pürüzlülüğunün Ve Kesme Önü Geometrisinin İncelenmesi. Pamukkale University J Journal of Engineering Sciences, 15(1).

Akkurt, A., Kulekci, M. K., Seker, U., \& Ercan, F. (2004). Effect of feed rate on surface roughness in abrasive waterjet cutting applications. Journal of Materials Processing Technology, 147(3), 389-396

Alberdi, A., Artaza, T., Suárez, A., Rivero, A., \& Girot, F. (2016). An experimental study on abrasive waterjet cutting of CFRP/Ti6A14V stacks for drilling operations. The International Journal of Advanced Manufacturing Technology, 86(1-4), 691-704.

Chanda, M., \& Roy, S. K. (2008). Industrial polymers, specialty polymers, and their applications (Vol. 74). CRC press.

Dong, Y., Liu, W., Zhang, H., \& Zhang, H. (2014). On-line recycling of abrasives in abrasive water jet cleaning. Procedia Cirp, 15, 278-282.

Gür, A. K., Taskaya, S., \& Çetin, Ö. (2019). Ramor 500 Çeliğinde Isıl İşlemin Mikroyapı, Mikrosertlik ve Abrasiv Aşınma Direncine Etkisinin Taguchi Metoduyla Değerlendirilmesi. Bitlis Eren Üniversitesi Fen Bilimleri Dergisi, 8(3), 1045-1056.

Gür, A. K., Ozay, C., Orhan, A., Buytoz, S., Caligulu, U., \& Yigitturk, N. (2014). Wear properties of Fe-Cr-C and B4C powder coating on AISI 316 stainless steel analyzed by the Taguchi method. Materials Testing, 56(5), 393-398.

Ishfaq, K., Ahmad Mufti, N., Ahmed, N., \& Pervaiz, S. (2019). Abrasive waterjet cutting of cladded material: kerf taper and MRR analysis. Materials and Manufacturing Processes, 34(5), 544-553.

Jose, A. J., \& Alagar, M. (2011). Development and characterization of organoclay- filled polyoxymethylene nanocomposites for high performance applications. Polymer composites, 32(9), 1315-1324.

Karakurt, İ., Aydın, G., \& Aydıner, K. (2010). Aşındırıcılı su jeti ile kesmede kesme parametrelerinin granit yüzey pürüzlülüğüne etkisi. Yerbilimleri Dergisi, 31(2), 99-110.

Kulekci, M. K. (2002). Processes and apparatus developments in industrial waterjet applications. International Journal of Machine Tools and Manufacture, 42(12), 1297-1306.

Kivak, T. (2014). Optimization of surface roughness and flank wear using the Taguchi method in milling of Hadfield steel with PVD and CVD coated inserts. Measurement, 50, 19-28.

Liu, X., Liang, Z., Wen, G., \& Yuan, X. (2019). Waterjet machining and research developments: a review. The International Journal of Advanced Manufacturing Technology, 102(5), 1257-1335.

Liu, H. T., Hovanski, Y., \& Dahl, M. E. (2012). Machining of aircraft titanium with abrasive-waterjets for fatigue critical applications. Journal of pressure vessel technology, 134(1).

Mardi, K. B., Dixit, A. R., Mallick, A., Pramanik, A., Ballokova, B., Hvizdos, P., \& Zelenak, M. (2017). Surface integrity of Mg-based nanocomposite produced by Abrasive Water Jet Machining (AWJM). Materials and Manufacturing Processes, 32(15), 1707-1714.

Mayuet, P. F., Girot, F., Lamíkiz, A., Fernández-Vidal, S. R., Salguero, J., \& Marcos, M. (2015). SOM/SEM based characterization of internal delaminations of CFRP samples machined by AWJM. Procedia Eng, 132, 693-700 
M, I. W., Azmi, A. I., Lee, C. C., \& Mansor, A. F. (2018). Kerf taper and delamination damage minimization of FRP hybrid composites under abrasive water-jet machining. The International Journal of Advanced Manufacturing Technology, 94(5-8), 1727-1744.

Nas, E., \& Altan Özbek, N. (2020). Optimization of the machining parameters in turning of hardened hot work tool steel using cryogenically treated tools. Surface Review and Letters, 27(05), 1950177.

Nas, E., \& Öztürk, B. (2018). Optimization of surface roughness via the Taguchi method and investigation of energy consumption when milling spheroidal graphite cast iron materials. Materials Testing, 60(5), 519525.

Roy, R. K. (2010). A primer on the Taguchi method. Society of Manufacturing Engineers.

Savaskan, M., Taptik, Y., \& Ürgen, M. (2010). Deney tasarımı yöntemi ile matkap uçlarında performans optimizasyonu. ITUÜDERGISII/d, 3(6).

Schwartzentruber, J., Spelt, J. K., \& Papini, M. (2017). Prediction of surface roughness in abrasive waterjet trimming of fiber reinforced polymer composites. International Journal of Machine Tools and Manufacture, 122, 1-17.

Shanmugam, D. K., \& Masood, S. H. (2009). An investigation on kerf characteristics in abrasive waterjet cutting of layered composites. Journal of materials processing technology, 209(8), 3887-3893.

Shanmugam, A., Krishnamurthy, K., \& Mohanraj, T. (2020). Experimental Study Of Surface Roughness And Taper Angle In Abrasive Water Jet Machining Of 7075 Aluminum Composite Using Response Surface Methodology. Surface Review and Letters, 27(03), 1950112.

Tabachnick, B. G., \& Fidell, L. S. (2007). Experimental designs using ANOVA (p. 724). Belmont, CA: Thomson/Brooks/Cole.

Taşdemir, M. (2019). Ticari Plastikler. Ankara : Seçkin Yayınları.

Vikram, G., \& Babu, N. R. (2002). Modelling and analysis of abrasive water jet cut surface topography. International Journal of Machine Tools and Manufacture, 42(12), 1345-1354. 